\title{
Evaluation of Performances of Intermodal Import-Export Freight Transport System in Ethiopia
}

\author{
Tadesse Kenea Amentae, Girma Gebresenbet \\ Department of Energy and Technology, Swedish University of Agricultural Sciences, Uppsala, Sweden \\ Email: tadesse.kenea.amentae@slu.se, girma.gebresenbet@slu.se
}

Received 14 January 2015; accepted 30 January 2015; published 3 February 2015

Copyright (C) 2015 by authors and Scientific Research Publishing Inc.

This work is licensed under the Creative Commons Attribution International License (CC BY). http://creativecommons.org/licenses/by/4.0/

(c) (i) Open Access

\begin{abstract}
Freight transport system that minimizes costs, increase conveniences, and environmentally safe has become the agenda worldwide since long before. This study was made with the main objective of assessing intermodal termed as "multimodal" freight transport service in Ethiopia. Data was collected by using structured questionnaire from randomly selected customers and multimodal freight transport section employees of Ethiopian Shipping and Logistics Service Enterprise. The study was made in two stages using customers: first, they were asked to evaluate their satisfaction with the multimodal freight transport system; second, to evaluate their comparative satisfaction with the segmented/"uni-modal" freight transport system against five major freight transport performance indicators. Customers were also asked to identify and rank top ten problems of freight transport logistics in Ethiopia. Data were analyzed using SPSS and excel sheets with descriptive statistics and the results were depicted using charts and tables. The study indicated that majority of customers were either dissatisfied or very dissatisfied with many of the performance indicators. The employees evaluated their organization as well performing relatively on more performance indicators. Both customers and employees evaluated the documentation performances as satisfying but cost and convenience as dissatisfying performances. Customers identified repetitive custom checking and waste of time in custom inspections process as the most severe problem in freight transport logistics in Ethiopia. The implementation of intermodal freight transport system to bring better change in import-export freight transport logistics of Ethiopia was in bitter challenge for customers due to a number of problems, except documentation performance that showed betterment.
\end{abstract}

\section{Keywords}

Freight Transport, Performance, Multi-Modal, Uni-Modal, Customers' Satisfaction, Employees' Evaluation, Ethiopia 


\section{Introduction}

\subsection{Background}

Ethiopia being one of the developing countries needs to be integrated with global economy and that can only be possible through efficient and effective flows of goods to and from the country in international trade. To this end, the country needs to adopt or develop an efficient intermodal transport system for freight transport. With the aim of improving the flow of goods between Djibouti port and dry ports in Ethiopia, Ethiopia implemented "multimodal" transport system since January 2011. The directive set by the government of Ethiopia [1] indicated that "multimodal" transport system in Ethiopia targets for seamless, low cost, and maximum customer convenient transporting of imported goods from Djibouti to dry ports in Ethiopia and the reverse flow in case of exported goods. On the other hand, news sources [2] indicated that the newly introduced integrated freight transport system was frustrating customers contrary to its intended objectives. Therefore, this study was made to assess the "multimodal" freight transport performance of Ethiopian Shipping and Logistics Service Enterprise (ESLSE) and to identify major constraints in Ethiopian import-export freight transport logistics that need due attention from stakeholders.

Ethiopia is a developing country in east Africa, which has a land area of about 1.1 million sq $\cdot \mathrm{km}$ and population of about 91.73 million [3]. See picture in the Annex.

\subsection{Literature}

\subsubsection{Overview of Freight Transport}

Today, households in many parts of the world use internet marketing on diverse commodities including fresh food items regardless of the season, which demands fast and reliable deliveries. These products may be produced thousands of miles away in other countries and continent. Central to these is the implementation of effective freight transport and logistics practice. According to [4], the long distance transportation of freight among countries internationally involves complex structure system. The integration of services and interaction among participants at different stages of the transport chain influences the success of trade. Today, the volume of freight transport is growing at high rate and crossing international borders. This growth resulted in an increase of congestion of road transport, which made intermodal freight transport to be among high priority agenda among the public, private players, and academia [5]. The authors indicated that particularly in Europe, intermodal transport is stimulated by governments to achieve a modal shift and to bring a more balanced use of different infrastructures (rail, sea, etc.) to accommodate the growth in transport volume instead of depending on road transport alone. As a result of its importance in international trade, freight transport industry has shown tremendous developments globally and today in many parts of the world integrated intermodal freight transport has become past innovation. On the other hand, the volume of international freight transport is ever increasing demanding more innovative and environment concerned freight transport system. For instance, according to [4] between 1998 and 2008 the world merchandise freight exports nearly tripled in value from $\$ 5.4$ trillion to $\$ 16$ trillion and US freight exports doubled from $\$ 682$ billion to $\$ 1.3$ trillion. [6] indicated that goods transport increased by more than 75\% for Europe between 1970 and 1997. The author noted that goods intermodal transport was also increasing and its volume has almost doubled rising from 113 million tone kilometer per year to 214 million tone kilometer per year only between 1990 and 1997.

\subsubsection{The Terms Intermodal, Multimodal, and Combined Freight Transport}

These terms are related and used by different sources sometimes in an overlapping way. [7] defined intermodal transport as an integration of shipments across modes. An integrated movement of freight that involve at least two modes of transport under a single through rate with a goal of providing seamless transport system from point of origin to the final destination under one billing and liability is known as intermodal transport [7]. [6] stated that intermodal, combined, and multimodal transports are terms used generally with freight transport. The author discussed definitions given by European Conference of Ministers of Transport (ECMT), the European Commission (EC), and the United Nations (UN). Here are three definitions cited in [6].

Definition 1: "Intermodal transport is the movement of goods (in one and the same loading unit or vehicle), which uses successively several modes of transport without handling of the goods themselves in transshipment between the modes". 
Definition 2: "Combined transport is a transport in which the major part of the European journey is carried out by rail inland waterways or sea and in which any initial and/or final leg carried out by road are as short as possible".

Definition 3: "Multi-modal transport is a carriage of goods by at least two different transport modes".

[8] distinguished among these terms as "multimodal" transport a system of transporting freight with a minimum of two different modes of transport in an integrated manner; inter-modal transport on the other hand is defined as a system of transport handing over one commodity with a minimum of two different modes of transport but within the same packaging, without any break. The author stated that combined transport as inter-modal transport of which the European legs are essentially carried out by rail, eventually inland waterways or sea, and initial or terminal legs, as short as possible, by road. The author stated that combined transport is a term which is commonly used in Europe and is an initiative to cover environment-friendly intermodal transport. According to [9] intermodal transport is a term within logistics which is the integration of shipments across modes. According to the author, the goal of intermodal transport is to provide seamless transport under one billing and common liability on the whole movement from origin to destination. [9] also noted that an intermodal transport as an alternative to reduce environmentally hazardous emissions through using less road transport. [9] also raised the fact that intermodal transporting is attracting interests from many actors including transport operators, politicians, engineers, and researchers resulted in many concepts and definitions which needs to be used contextually. [10] also indicated that the increased attention to intermodal transport, particularly intermodal freight transport is as a result of problems of road congestion, environmental concerns, and traffic safety. The author noted that an increasing attention to speed and agility in supply chain is a driving force for firms to reconsider usual logistics service and intermodal is a result in transport logistics. The author noted, with European Union (EU), UN Economic Commission for Europe, European Conference of Ministers of Transport, intermodal transport is a notion that concerns with the movement of goods in one and the same loading unit (e.g., container, vehicle), which uses successively several modes of transport without handling the goods while changing modes. [9] explained multimodal transport is characterized by essentially separate movements involving different modes while intermodal transport is integration of shipments across modes including the same billing system. This explanation was also confirmed by [7] and is not the same on the definitions given to multimodal transport by the United Nations Convention for "multimodal" transport of goods, by EC as cited in [6] and by [8]. [9] explained combined transport in the same way with [8], as intermodal transport of unitized cargo when the major part of the journey is by rail any initial or final leg is carried out by road.

From these definitions, it is clear that these terms are used by different people at different contexts. The terms involve many concepts in common though lesser differences in definition exist among authors, particularly on "multimodal" versus "intermodal". The involvement of at least two modes of transport, concern for environment, single billing, single liability and integration among the modes are major issues and features that were discussed. Though, terms can be used based on the definition given for each situation, for integrated movement of freight that involve at least two modes of transport under a single billing and liability, authors believe the term "intermodal" is better used for the prefix "inter" in "inter-modal" stands to show the integration among modes but the prefix "multi" in "multi-modal" only shows the existence of more than one mode of transport but not an integration among the modes.

\subsubsection{Advantage of Integrated Transport}

The common objectives of integrated transport arrangements are efficient and effective goods flow from one point to the other. These are key arrangements to development as no country can develop without trade and transportation is central gravity of effective and efficient trade. Intermodal transport service gives collected responsibility for transport activities under one operator. Then it is the responsibility of operator to manage and coordinate the total activities from shippers' door to buyers' door.

The rise of international intermodal transport service is the result of its benefit over the separate mode arrangements. Many studies showed that intermodal transportation of goods saves both money and time. [10] claimed that ten transportation days could be saved on cargo shipment from Far East to New York by using intermodal arrangement over a segmented routes.

Efficient transitions between modes, flexibility and possibilities for door-to-door service, environmental advantage, and the possibilities of combining the advantages from separate modes are noted to be advantages of intermodal transport system by [11]. Similarly, [12] noted that intermodal transport system is a response to cus- 
tomers' demand to get one-window, integrated, just-in-time, efficient and all inclusive door-to-door service at predetermined price.

[11] indicated that the use of multimodal transport has a benefit of enhancing competitiveness of the freight industry as a whole through use of most efficient mode of transport at each stage. The author explained the benefit of multimodal transport from legal point of view and claimed five major benefits of multimodal transportation arrangements. These are: avoiding of separate arrangements of contracting with many transporters, avoiding the hassle of the shipper for placing goods at the right place at the right time for each of the contracting transporting segments, avoiding the inconvenience of storing goods between different segments of the transport stages when the segments don't fit seamlessly, the negotiability of bill of lading of multimodal transport arrangements to acquire a documentary credit from banks contrary to other consignment notes such as road carriers notes which are not negotiable, and finally avoiding the difficulty of assigning responsibility/liability in case of damage which may be complex under segmented arrangements with difficulty of identifying at which stage of the segment the damage occurred.

\subsubsection{Intermodal Concept and Development in Ethiopia}

Intermodal transport concept is just at its infant stage in Ethiopia. The system was started on January, 2011 by Ethiopian Shipping and Logistics Service Enterprise. The term "multimodal" was used instead of intermodal but with the same meaning of intermodal, i.e., to provide seamless transport under one billing and liability on the whole movement from origin to destination. The "multimodal" transport system was introduced with the aim of easily moving freight from port Djibouti on time. The system was started after the issuance of Multimodal Transport Implementation Directive on July 2010 by Ethiopian government. The directive defined the multimodal transport system as "a system whereby transportation of goods is under a single contract but performed by more than two means of transportation; the carrier is liable for the entire journey including the shipment's delivery at final destination; the transportation can be made by sea, rail, and trucks (roads).” This definition is the same with what is given for intermodal transport system.

\subsubsection{Challenges of Integrated Freight Transport}

[6] called the challenges to intermodal transportation as "barriers or critical success factors". The author identified five types of challenges to intermodalism as: "hardware", "software", "orgware”, "finware”, and "ecoware”. The author explained that hardware challenge includes compatibility of technology, intermodal competition, and complementarities; software includes compatibility of information system; orgware is a challenge of design and management of ports, terminals and transfer points; finware is a matter of cost effectiveness and user charges; The sustainability (reducing the market share of road transport for appropriate balance with others to bring overall efficiency and safety of transport operations and to reduce pollution and congestion is the last but not least challenge named as ecoware. These challenges identified by the author were more or less the same with the challenge identified by United Nations. According to standing committee of United Nations Council on Trade and Development report on fostering competitive "multimodal" transport services [13] the challenges of "multimodal" transport were seen from two perspectives. The first is the capacity of rendering multimodal transport service, particularly by developing countries, i.e., the development of multimodal transport requires globalization of production and liberalization of services which demands higher capabilities for countries to offer reliable and cost effective transport and logistics services. Countries need to develop their capacity so as to take advantages of technological developments. The second challenge indicated was need of harmonization of the legal environment for intermodal transport particularly considering the development of international transport demands the harmonization of the legal environment. However, the progress in this respect was a non-ratified document of United Nations convention on international multimodal transport of goods since May 1980.

In case of Ethiopia, the challenge of intermodal system is presently two fold. First, the country's capacity to provide intermodal transport service that is reliable and cost effective is dependent on the use of advanced technology and infrastructure. In this regard, Ethiopia's challenge may be more severe than elsewhere because the country presently has no operational rail transport system and the transport infrastructure in road sector is also not developed to the required level. Second, Ethiopia began the service very recently (2011) and the experience of the system to the country is new phenomenon. As the intermodal transport system is implemented recently its performance needs to be evaluated for possible solutions. In general, the five challenges mentioned by [6] the "hardware", "software", "orgware", "finware”, and "ecoware” are all relevant challenges to Ethiopia in imple- 
mentation of intermodal freight transport.

This study was made to address the second challenge of Ethiopian multimodal freight transport. The system which was intended for reliable, efficient, maximum customer convenient transport system under one billing and liability was evaluated by customers and employees. The study identified problem areas that need further research and interventions to overcome the challenges if Ethiopia has to get benefits from integrated freight transport system.

\section{Objective of the Study}

The main objective of this study was to evaluate the intermodal freight transport service performance of Ethiopian Shipping and Logistics Service Enterprise (ESLSE) ${ }^{*}$ by its customers and employees. The specific objectives were to evaluate the ESLSE's:

o delivery performance,

o transportation documentation performance,

o performance on liability and insurance during damage or loss of goods while in transit,

o transport service cost and associated costs \& convenience,

o administrative support service provided,

o comparative customers' satisfaction on the above five performance indicators on "multi-modal" versus "unimodal" (with different billings of the same goods) approaches, and

o To identify major problems in fright transport logistics of Ethiopia.

\section{Material and Methods}

\subsection{Sampling and Data Collection}

The total numbers of ESLSE's customers were not known because it has no registered customers. Therefore, sampling formula was not applied. Instead, the data was collected from customers coming for service to ESLSE over an extended period of time in two stages. The first phase of data collection, which was made during May to September 2013, was to evaluate their satisfaction on the "multimodal" transport service. The second phase was conducted between June-September/2014 on the comparative analysis between "multi-modal" versus "uni-modal" freight transport service. ESLSE calls "uni-modal" approach to segmented freight transport system with multiple bills and liability. Totally, 102 customers who have used both "multi-modal" and "uni-modal" freight transport service from ESLSE have responded to the survey. The data from employees was collected in first phase period from all employees (22) of multimodal transport section of Ethiopian Sipping and Logistics Service Enterprise at enterprise's head quarter, Addis Ababa.

\subsection{Data Collection Tools}

Both primary and secondary data were used in this study. For primary data collection purpose, survey questionnaire was used. Both customers and employees were approached personally and asked to fill the questionnaire; explanations were given to the respondents where they need.

\subsection{Analysis}

Satisfaction was measured through a psychometric 5-point Likert scale. The five categories of response were: 1 , Very dissatisfied; 2, Dissatisfied; 3, Neutral; 4, Satisfied; and 5, Very satisfied. This scale was used to measure strength of opinion of selected service attributes. The use of a 5-point Likert scale allows for the balanced collection of respondent opinion through an equal number of positive and negative categories [14]. Similarly, employee evaluation was also made in 5-point rating scale where: 1) Strongly disagree; 2) Disagree; 3) Neutral; 4) Agree; and 5) Strongly agree. The questions addressed to customers and employees were the same but in different ways so as to make comparison possible. Customers were asked how much they were satisfied with the service and employees were asked how they evaluate particular service performance. Descriptive statistics were used in analyzing the collected data.

Customer satisfaction as performance measure has many benefits. For instance, [15] stated that customer satisfaction is an attribute that evaluates organizational goal achievements. The authors emphasized that organiza-

\footnotetext{
*Ethiopian Shipping and Logistics Service Enterprise (ESLSE) is a state owned sole "multimodal” freight transport operator in the Ethiopia.
} 
tions can evaluate their performance by how much they satisfy their customers with greater efficiency and effectiveness than their competitors. [16] also noted that customer satisfaction is a key criterion for evaluating the quality that is actually provided to customers by products or services. [17] indicated that high level of service through awareness of customer expectations and improvements in services or products is a matter of organizations survival. Different methods can be employed to evaluate the quality of services and customer satisfaction. [17] sated subjective or soft measures of quality which focus on perceptions and attitudes of the customer rather than more concrete objective criteria are most common methods used in customer satisfactions surveys. For this study, customer satisfaction survey was made for the purpose of identifying problem areas or effectiveness measure of [15] for improvement of the "multimodal" transport service by ESLSE. Expectancy disconfirmation approach was the assumption of this study, where customers' and employees' expectations on the service performance of the performance indicators are compared or "psychologically processed" against the actual performance to bring satisfaction or dissatisfaction [18].

\section{Performance Evaluation Checklist for This Study}

[17] soft or subjective measure approach was used with survey questionnaires to evaluate customers' and employees' attitude and perceptions of the quality of service they were receiving and rendering based on five performance indicators namely: Delivery performance, Documentation performance, Liability and Insurance performance, Cost and Convenience performance, and Facilitation performance. These performance indicators were developed by authors based on the content of United Nations Convention for the international multimodal freight transport [19] and common freight transport service parameters.

\section{Result}

\subsection{Customers' Evaluation}

\subsubsection{Customers' Evaluation of Delivery Performance}

The delivery performance was assessed on five performance indicators namely: departure accuracy, the accuracy of time promised for the shipment to reach the destination, instructional clarity on delivery, tracking information, and overall delivery performance. The result is presented in Figure 1.

From Figure 1, significant numbers of customers were not satisfied on all of delivery performance indicators. On overall delivery performance, $56 \%$ of the customers responded that either dissatisfied (37\%) or very dissatisfied (19\%). Similarly, for departure accuracy, promised running times, instruction clarity, and tracking information the cumulative of dissatisfied and very dissatisfied customers was more than the cumulative of satisfied and very satisfied customers.

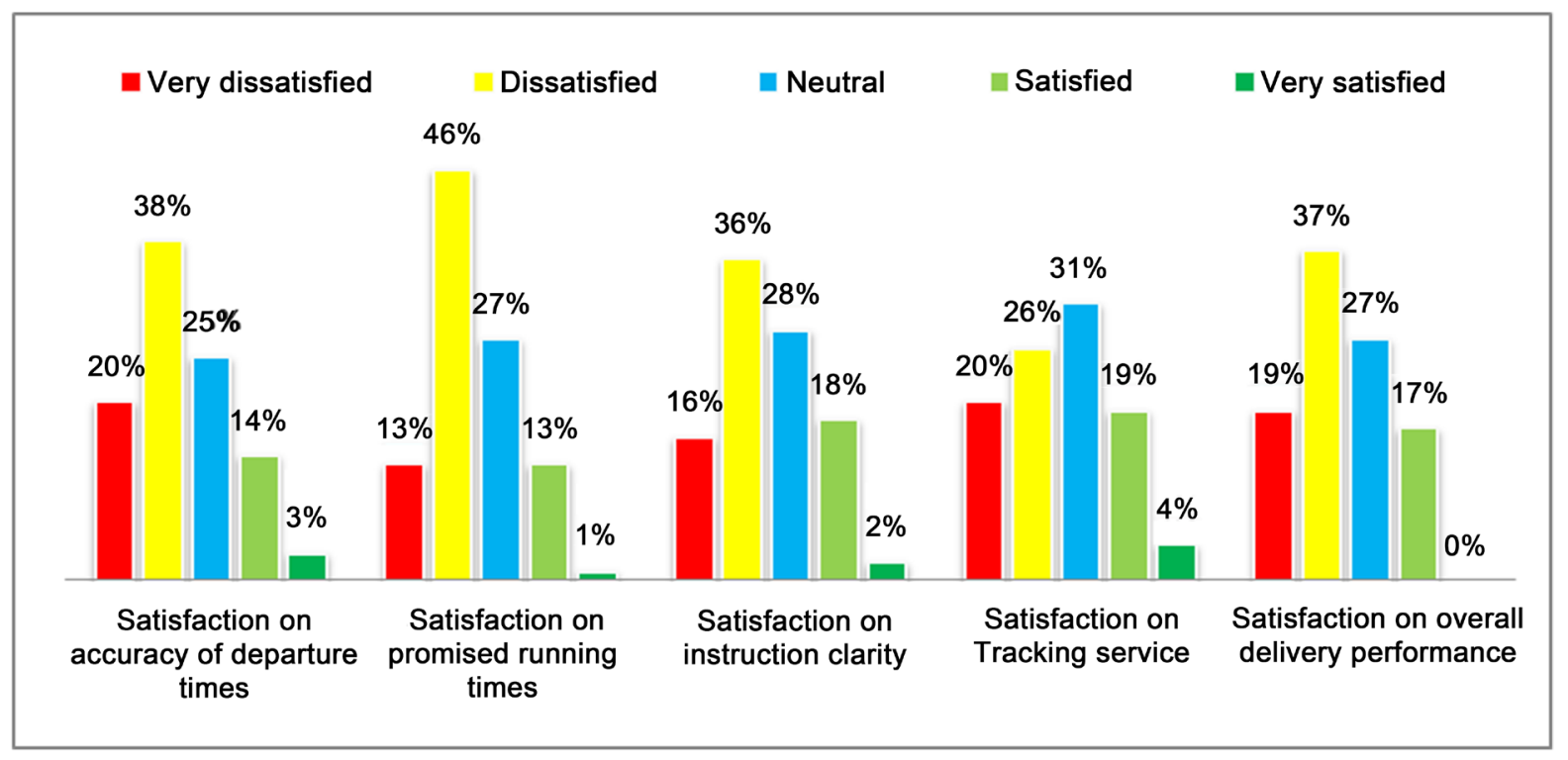

Figure 1. Customers’ satisfaction on delivery performances. 


\subsubsection{Customers' Evaluation of "Multimodal" Transport Documentation Performance}

The result of "multimodal" transport documentation performance is presented in Figure 2. The assessment was made for proper issuance and delivery of transport document, custom documentation handling and delivery, transport document confidentiality, and for overall documentation performance related to multimodal service.

The result presented in Figure 2 indicated that the organization performs well in terms of performance indicators under transport documentation issues. For overall documentation performance, 59\% respondents were in satisfied (50\%) and very satisfied (9\%) response category. Similarly, on timely issuance and delivery of transport documents, enclosure and delivery of custom documents and confidentiality of the documents, the majority of respondent customers were either satisfied or very satisfied.

\subsubsection{Customers' Satisfaction on Liability/Insurance in Case of Loss or Damage of Freight}

The assessment for this section were made for four performance indicators: accident reporting, claim presentation to insurer in case of loss, the follow up of the company on claims to the insurer, and finally how customers feel that they are safe for their cargo in terms of loss or damage. The results on these indicators were presented on Figure 3.

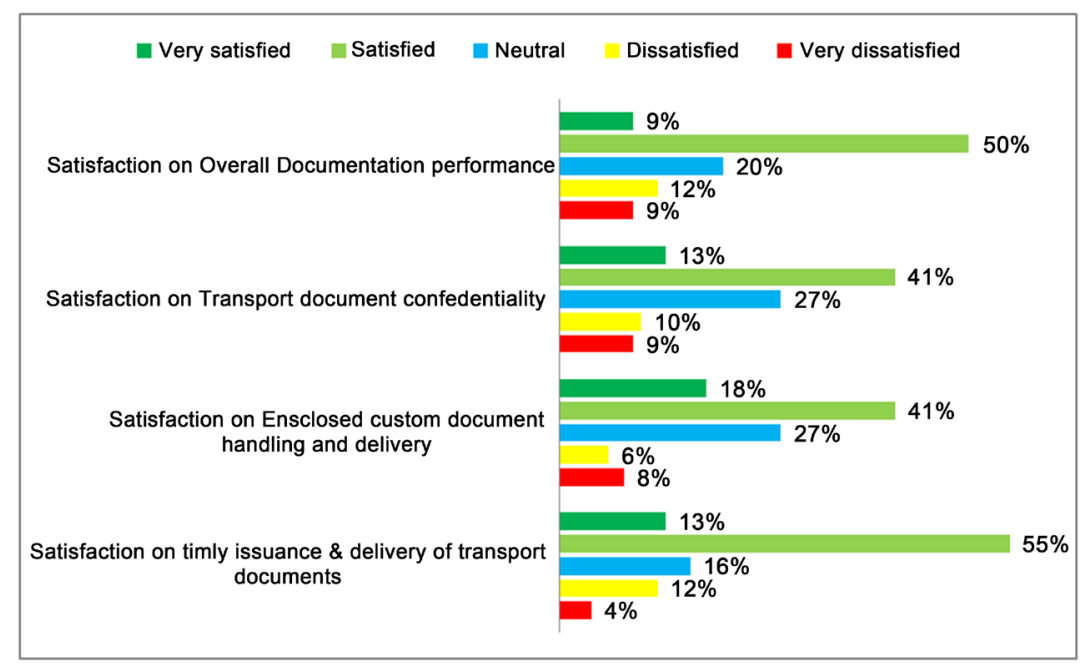

Figure 2. Customers' satisfaction on documentation performances.

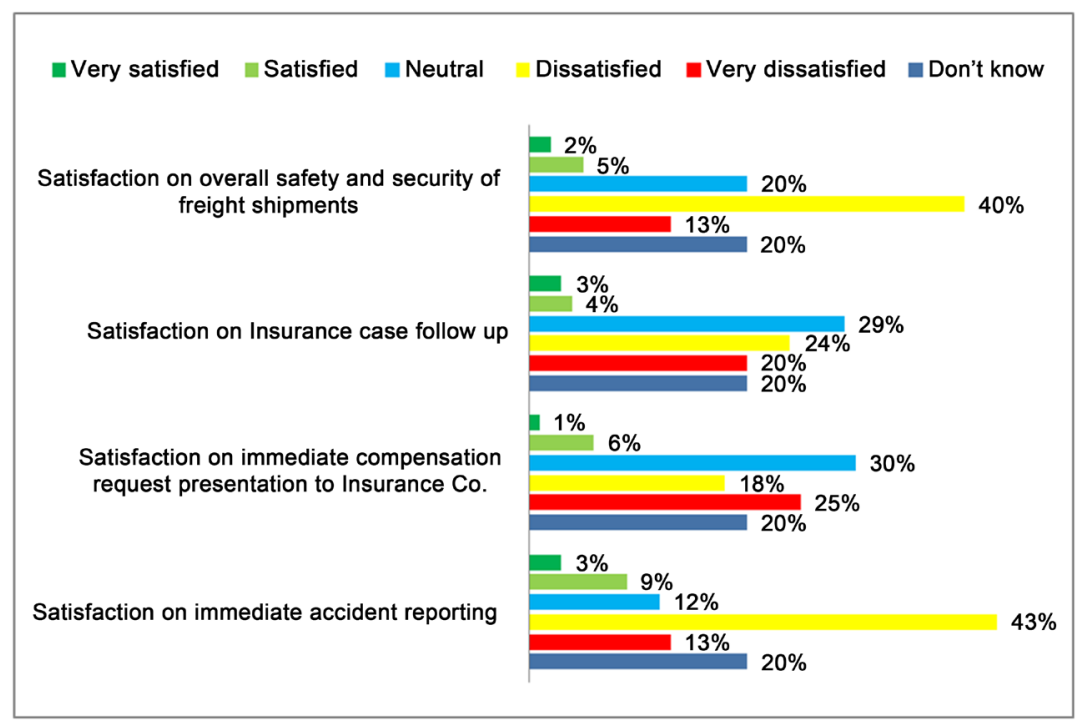

Figure 3. Customers' satisfaction on liability and insurance in case of freight loss or damage. 
The result presented in Figure 3 indicated that 20\% of the respondent customers responded that they don't know the case, which means they never encounter freight loss or damage. This also indicated the existence of frequent loss or damage to freight as $80 \%$ of the respondent customers know the loss cases. The organization's performance on safety and security for their freight seems frustrating, in all the performance indicators majority of the customers were either dissatisfied or very dissatisfied.

\subsubsection{Customers' Satisfaction on "Multimodal" Transport Cost and Conveniences}

Figure 4 presents the result of cost and convenience performance indicators.

The assessments were made on customers' satisfaction on clarity of cost, fairness of the transportation cost, fairness of other associated costs, loading unloading place convenience, and loading unloading infrastructure conveniences.

According to Figure 4, the survey result indicated that majority of the customers were unhappy with the cost and convenience matters. In all the evaluation performance indicators assessed, there was no criteria for which very satisfied customer response was clearly visible. Majority of the respondent customers were not happy with cost clarity, its fairness, place, and machinery conveniences. The cumulative of dissatisfied and very dissatisfied was more than $60 \%$ in all the cost and convenience related performance indicators.

\subsubsection{Customers' Satisfaction on Facilitation Support by ESLSE}

The assessment for this performance was made in terms of satisfaction on support provided through simplification of procedures and formalities with different organizations through information sharing by Electronic Data Interchange (EDI), cooperation in customs automation and efficient tariff arrangement, and banking facilitation. The results were presented in Figure 5.

According to Figure 5, for banking service facilitation, the cumulative of satisfied and very satisfied customers was equal with the cumulative of dissatisfied and very dissatisfied respondent customers (31\%). On simplification through Electronic Data Interchange (EDI) and custom automation support the proportion of dissatisfied and very dissatisfied customers exceeds those in satisfied and very satisfied response.

\subsection{Employee Evaluation of "Multimodal" Service}

\subsubsection{Employees' Evaluation of Delivery Performance}

Employees were asked to evaluate Ethiopian Shipping and Logistics Service Enterprise's performance in relation to the same delivery performance indicators with section 4.1. The results of the assessment were presented in Figure 6.

As presented in Figure 6, majority of the employees feel that their organization is performing well in terms of promised running times, tracking information and overall delivery performances; for these indicators the cumulative of strongly agree and agree to well performance exceeds the sum of disagree and strongly disagree. In contrast, in terms of promised departure time and instruction clarity, more employees responded that their organization was not doing well.

\subsubsection{Employees' Evaluation on "Multimodal" Document Performance}

Performance indicators under section 4.2 were also assessed by employees in relation to multimodal transport documents. The results of assessment were presented in Figure 7.

According to Figure 7, 58\% of respondent employees agree that the organization is performing well in terms of overall documentation. In all the other performance indicators under documentation, the cumulative of agree and strongly agree to well performance are more than the proportion of employees who responded either disagree or strongly disagree

\subsubsection{Employees' Evaluation on Liability and Insurance in Case of Loss or Damage}

The assessments under this section were made in respect of four major points of evaluation and the results were presented in Figure 8.

From Figure 8, majority (53\%) of respondent employees responded that their company was doing well in terms of overall addressing safety and security of freight shipments against loss and damage. Similarly, majority of respondent employees agree or strongly agree that the organization is doing well with regards to: timely accident reporting, compensation claim presentation to insurer and claim follow ups. 


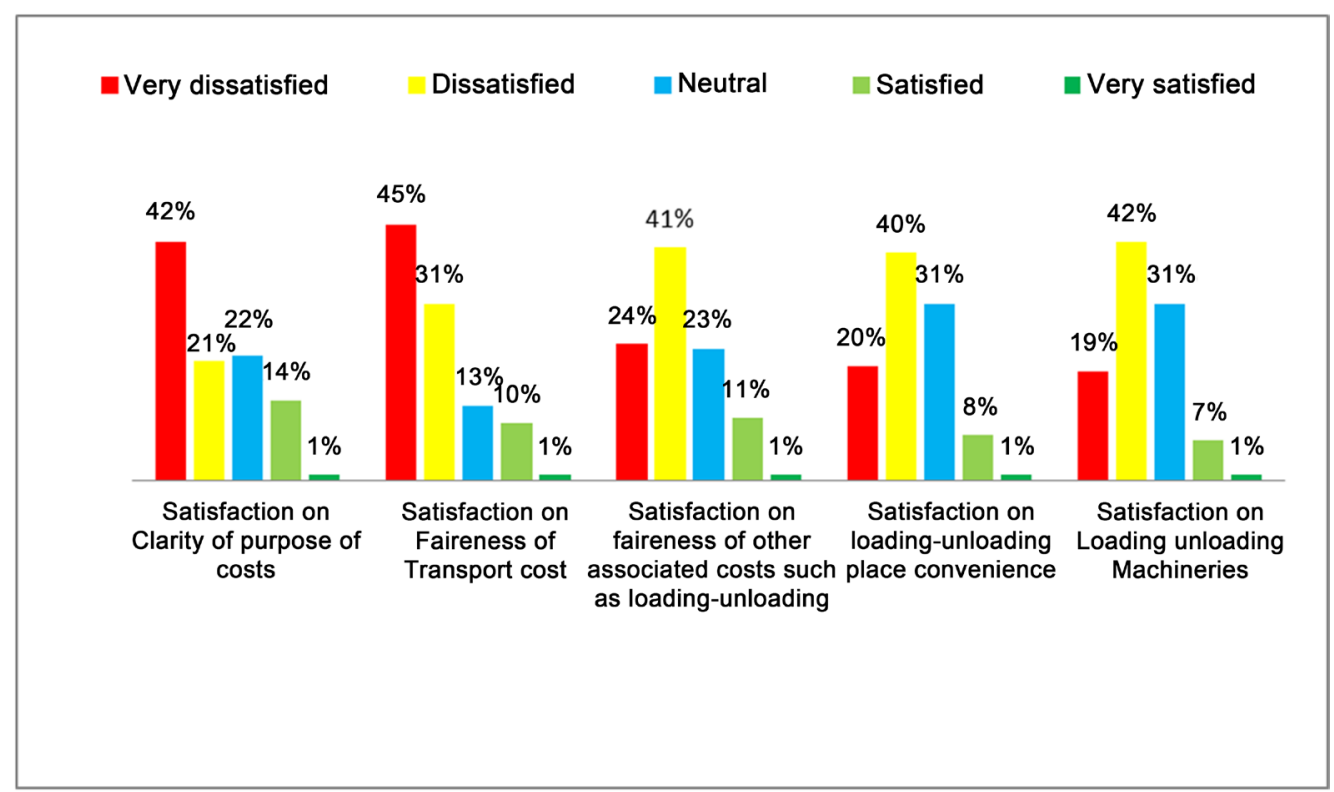

Figure 4. Customers' satisfaction on cost and convenience.

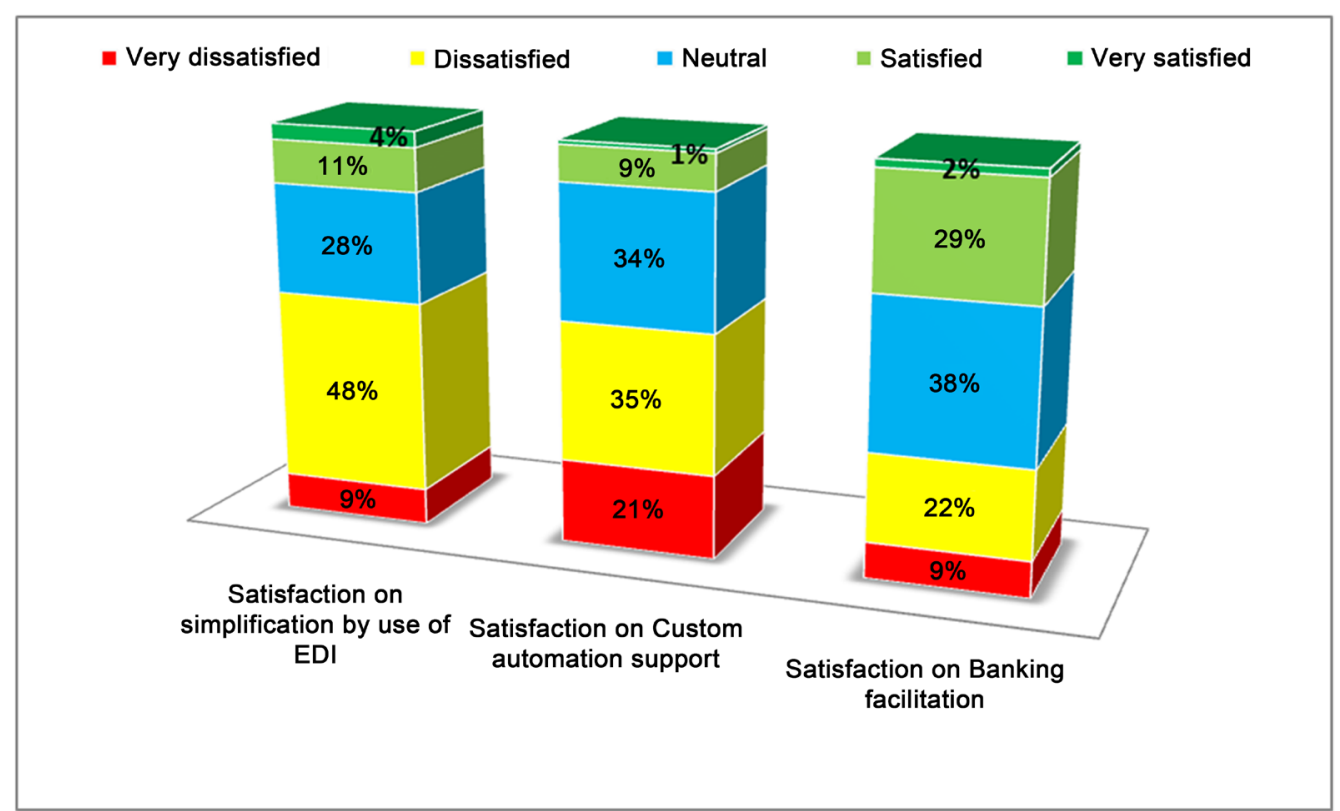

Figure 5. Customers' satisfaction on facilitation service related to multimodal freight transport.

\subsubsection{Employees' Evaluation on Cost and Convenience Related to Multimodal Transport}

The results of the employee assessment which were made in terms of five criteria related to cost and convenience were presented in Figure 9.

The results in Figure 9 indicated that majority of the respondent employees responded they either disagree or strongly disagree that the purpose of costs were clear, transportation and associated costs were fair, and the organization has enough required machineries. Majority (48\%) of them responded that they agree or strongly agree that the places for loading-unloading were convenient.

\subsubsection{Employees' Evaluation on Administrative and Facilitation Service}

The evaluation results which were made on three evaluations points were presented in Figure 10. 


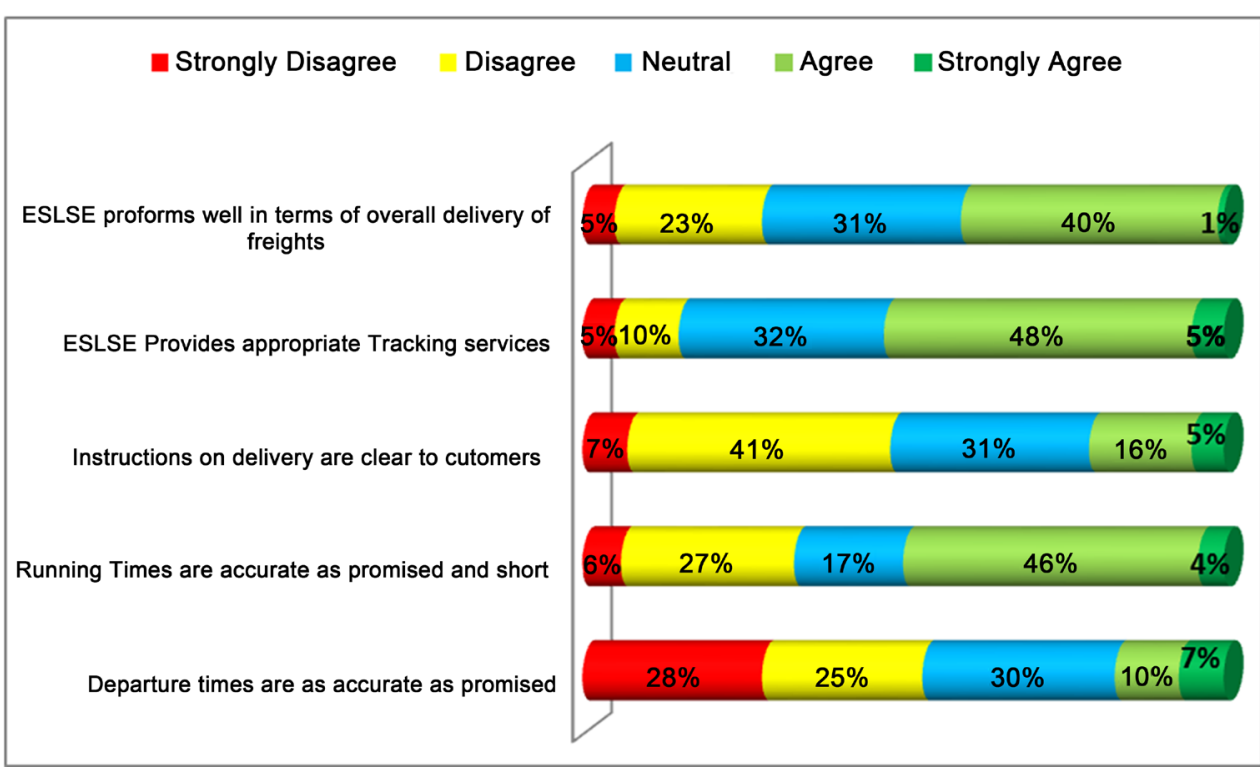

Figure 6. Employees’ evaluation of delivery performances.

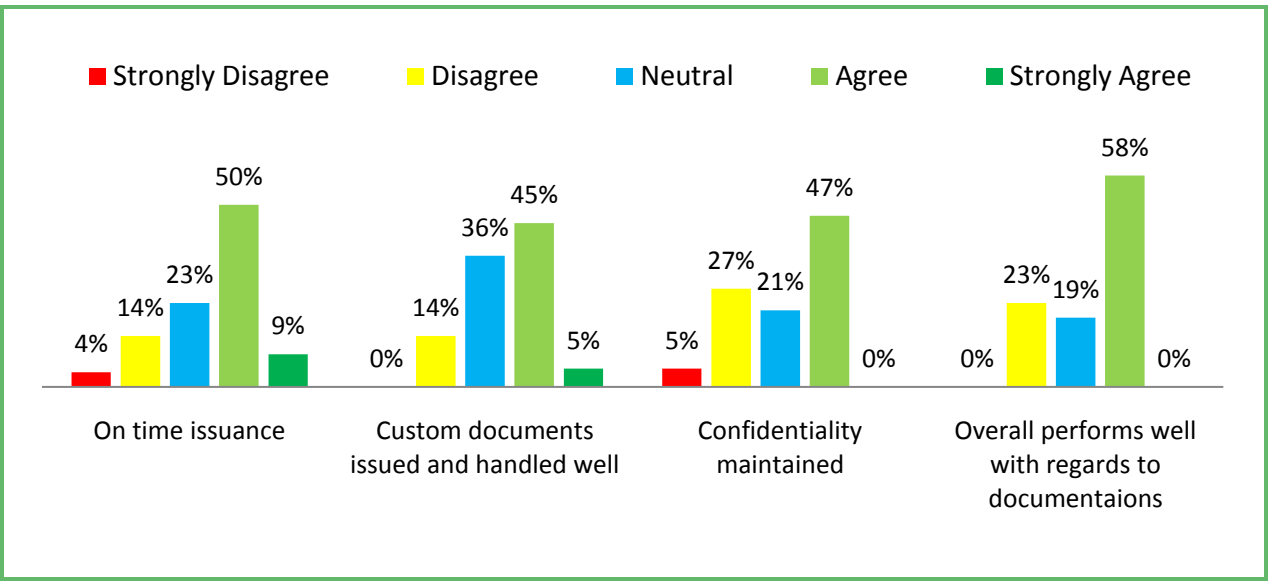

Figure 7. Employees' evaluation of on documentation performances.

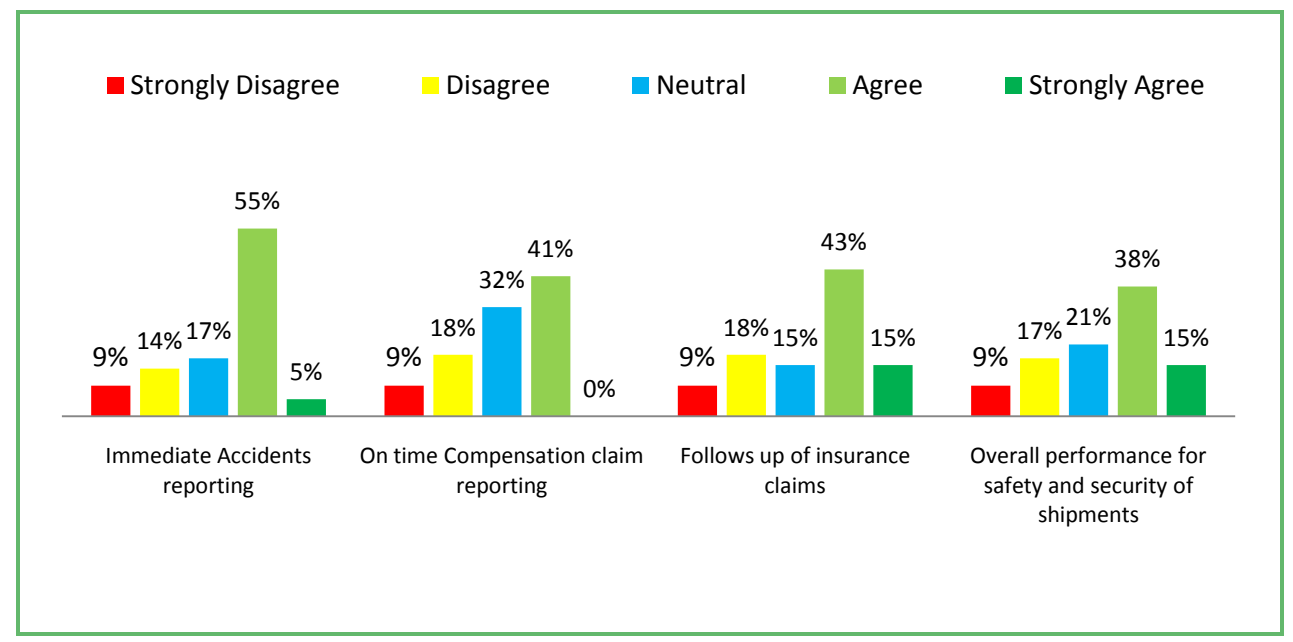

Figure 8. Employees' evaluation on liability and insurance performance indicators. 


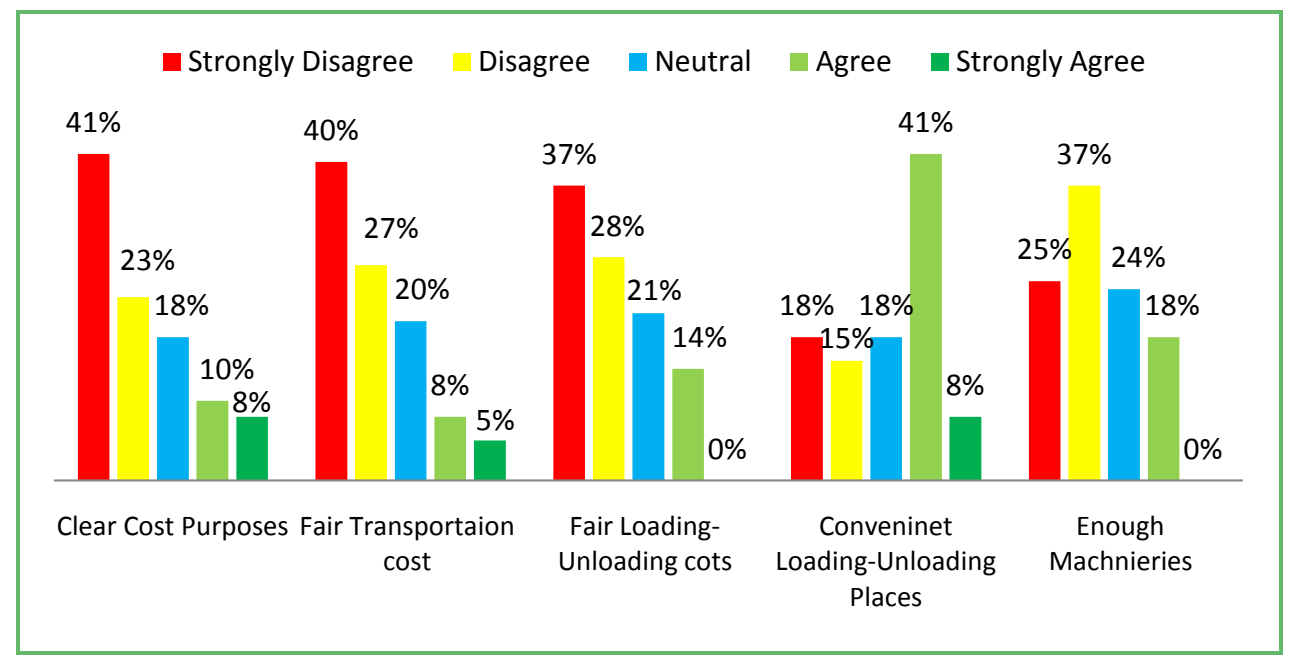

Figure 9. Employees' evaluation on cost and convenience performances.

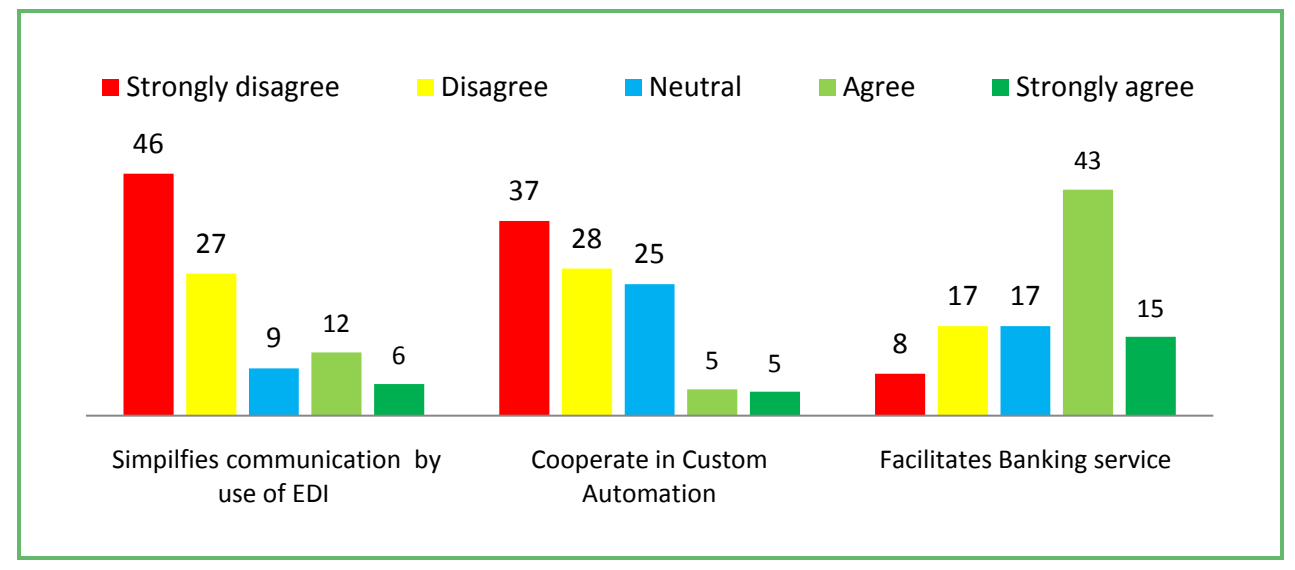

Figure 10. Employees’ evaluation on facilitation services.

Results presented in Figure 10, indicated that the company was doing well in terms of banking facilitation but simplification of communications through EDI and cooperation in custom automation did not meet employees' expectation.

\subsection{Comparative Analysis with "Uni-Modal” Approach}

The result of comparative analysis which was assessed by customers who have already used services of ESLSE under both segmented and integrated approaches was presented in Figure 11.

According to the result, presented in Figure 11, out of the 21 performance indicators used in this study on 66\% (14) pointed that the "uni-modal" line was above the "multi-modal" line, i.e., in these points majority of customers responded the "uni-modal" system satisfied them than the multi-modal approach. Looking at Figure 11, the organization was better satisfying its customers in documentation related performance indicators under the "multi-modal" approach. The big distance between the two lines, $(92,8 ; 90,10)$ coordinates for "uni-modal" and "multimodal" respectively, were assessment for transport cost and related costs. That is, big majority of respondent customers were dissatisfied with the costs under "multi-modal" freight transport system.

\subsection{Top Ten Constraints in the Ethiopian Import-Export Freight Transport Logistics}

The respondent, customers were given with a lists of possible constraints and asked to rank top ten problems from top severe to least severe as 1 to 10 ( 1 top severe and 10 least severe). Customers were also given the possibility to add and give rank to any other constraints they know which were not in the list. The result of this was 
presented in Table 1.

From Table 1, majority of customers responded that repetitive custom check and high time waste during custom inspections process is the most severe problem, ranked $1^{\text {st }}$ by $47 \%, 2^{\text {nd }}$ by $22 \%$, and $3^{\text {rd }}$ by $26 \%$ and $4^{\text {th }}$ by $5 \%$ of respondents. In Table 1, the cells were highlighted for red, yellow, and light blue colors for problems which were considered top four severe, fifth to seventh, and eighth to tenth problems respectively by customers. Just looking on the maximum response under each rank column, the problems can be ranked from repetitive custom check and high time waste as the most severe problem, ranked $1^{\text {st }}$ by $47 \%$ to service providers' problem as least ranked problem, ranked $10^{\text {th }}$ by $78 \%$.

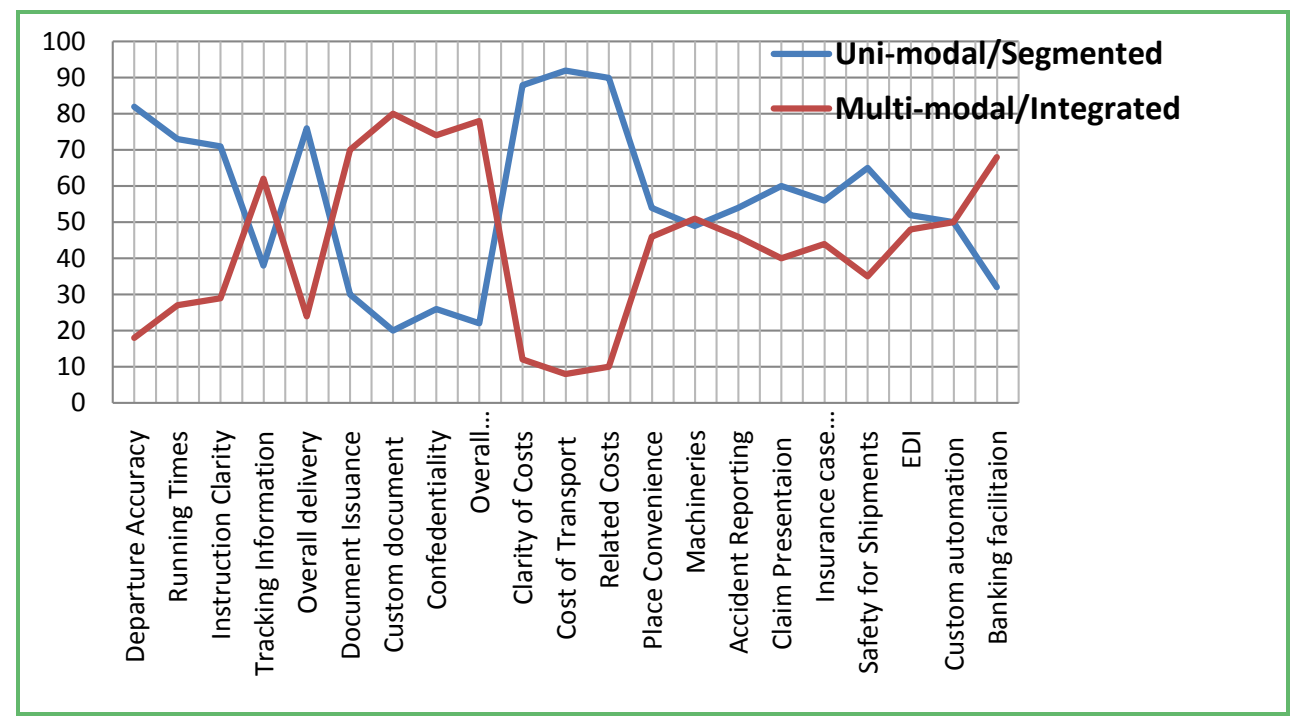

Figure 11. Comparative performance evaluation on "multi-modal” versus "uni-modal” freight Transport.

Table 1. List of top ten problems in Ethiopian Freight Transport Logistics.

\begin{tabular}{|c|c|c|c|c|c|c|c|c|c|c|c|c|}
\hline \multirow{2}{*}{ S. $\mathbf{N}$} & \multirow[b]{2}{*}{ Prolems: } & \multicolumn{11}{|c|}{ Percentage of Respondent who ranked the problems } \\
\hline & & $1^{\mathrm{st}}$ & $2^{\text {nd }}$ & $3^{\text {rd }}$ & $4^{\text {th }}$ & $5^{\text {th }}$ & $6^{\text {th }}$ & $7^{\text {th }}$ & $8^{\text {th }}$ & $9^{\text {th }}$ & $10^{\text {th }}$ & Total \\
\hline 1 & $\begin{array}{l}\text { Repetitive custom check and high time } \\
\text { waste during custom checking process }\end{array}$ & 47 & 22 & 26 & 5 & & & & & & & 100 \\
\hline 2 & $\begin{array}{l}\text { Monopoly of Freight Transport service } \\
\text { by ESLSE }\end{array}$ & 22 & 26 & 35 & 9 & 4 & & 4 & & & & 100 \\
\hline 3 & $\begin{array}{l}\text { Complete dependence on Djibouti port } \\
\text { for multimodal system }\end{array}$ & 17 & 22 & 26 & 18 & 17 & & & & & & 100 \\
\hline 4 & $\begin{array}{l}\text { Basic Infrastructure } \\
\text { (roads, bridges, etc.) }\end{array}$ & 4 & 21 & 4 & 22 & 18 & 9 & 18 & 4 & & & 100 \\
\hline 5 & $\begin{array}{l}\text { Fragmented Management of } \\
\text { Freight Logistics Sector }\end{array}$ & 10 & 9 & 4 & 22 & 22 & 13 & 7 & 13 & & & 100 \\
\hline 6 & Traffic Accidents & & & & 13 & 13 & 17 & 18 & 26 & 9 & 4 & 100 \\
\hline 7 & Problems at Dry Ports & & & & 4 & 17 & 26 & 9 & 26 & 13 & 5 & 100 \\
\hline 8 & Transistors' problems & & & 5 & & 9 & & 35 & 17 & 30 & 4 & 100 \\
\hline 9 & Transporters' problems & & & & 7 & & 31 & 9 & 18 & 26 & 9 & 100 \\
\hline 10 & $\begin{array}{l}\text { Other service providers' problems } \\
\text { (insurance, banks, etc.) banks, etc.) }\end{array}$ & & & & & & 4 & & & 18 & 78 & 100 \\
\hline & Total & 100 & 100 & 100 & 100 & 100 & 100 & 100 & 100 & 100 & 100 & \\
\hline
\end{tabular}




\section{Discussions}

In most cases, customers were not satisfied with performances under the "multimodal" freight transport service. However, employees evaluated some points as well performing contrary to customers' evaluation. This may emanate from two reasons: first, employees as the service providers may not really feel the hassle customers were facing; second, method used in this study, had joint focus group discussion was made with customers and employees, both customers and employees could have been near to each other on evaluation. Regardless of this, the organization has to review its service performances particularly in terms of cost and convenience where both customers and employees evaluated the company negatively. The result of customer evaluation was also same with other news sources [1] and [2] that indicated the newly implemented "multimodal" freight transport system in Ethiopia was frustrating customers.

From this study, it is evident that ESLSE faced challenges in implementation of multimodal freight transport system in the country. However, desired intention of the "multimodal" transport system for Ethiopia is not an option rather a must to proceed if Ethiopia has to benefit from international trade and development. To this end, the role of every stakeholder in the sector has to be further investigated and detail and planned work is required in terms of alleviating problems identified in this study and also the role of research studies to identify knowledge gap and solutions to the problems are critical \& timely issues. In this regard the following points are believed for further study:

1) An assessment of custom terminal checking procedure and process at port Djibouti, Ethiopia boarder terminal, and all the ways to dry ports in Ethiopia: what can be done in this regard?

2) Why costs of "multimodal” freight transport in Ethiopia is high?

3) Is it possible to think of privatization of the "multimodal” freight transport system in Ethiopia to improve the implementation of system?

4) To what extent can the planned railways in Ethiopia contribute to improvement of freight transport in Ethiopia?

5) Alternative analysis of possible ports that Ethiopia can use to avoid complete dependence on Djibouti port.

\section{Conclusion}

This study was made on customer satisfaction and employee evaluation of the "multimodal” transport service performance of ESLSE. The result indicated that majority of the customers were not satisfied with many of the service performances. In contrast, employees evaluated their organization positively on many performance indicators. The comparative analysis made with "uni-modal” approach for customers indicated that the "multimodal” system which was supposed to improve the service performance did not even satisfied customers as much as the "uni-modal" approaches on majority of the performance indicators used in this study. Customers also listed top ten problems of freight transport logistics in Ethiopia where repetitive custom checks and high waste of time during custom checking process were ranked as the most severe constraint.

\section{References}

[1] Fortune Newsletter (2012) Government of Ethiopia Evaluating Technical Proposals from Six International Companies on the Multimodal Transport System, Vol. 13, No. 659. 16 December 2012.

[2] Addis Ababa Chamber of Commerce \& Sectorial Associations (AACCSA) (2012) Meeting Assessment Report. December 2012.

[3] World Bank (2012) Ethiopia at a Glance.

[4] US Department of Transportation (2010) Freight Transportation, Global Highlights.

[5] Bontekoning, Y.M., Macharis, C. and Trip, J.J. (2004) Is a New Applied Transportation Research Field Emerging?-A Review of Intermodal Rail-Truck Freight Transport Literature. Transportation Research Part A, 38, 1-34. http://dx.doi.org/10.1016/j.tra.2003.06.001

[6] Janic, M. (2001) Integrated Transport System in European Union: An Overview of Recent Developments. Transport Review, 21, 469-497. http://dx.doi.org/10.1080/01441640110042147

[7] Brewer, A.M., et al. (2001) Handbook of Logistics and Supply Chain Management. Elsevier Science Ltd., London.

[8] Ballis, A. and Golias, J. (2003) Towards the Improvement of Combined Transport Chain Performance. European Journal of Operations Research, 152, 420-436. 
[9] Kihlström, M. (2003) Possibilities for Intermodal Grain Transports in Mälardalen Region-Environmental and Economic Aspects, M.Sc. Thesis, Swedish University of Agricultural Sciences, Uppsala.

[10] Hoeks, M.A.I.H. and Breda (2009) Multimodal Transport Law-The Law Applicable to the Multimodal Contract for the Carriage of Goods. Kluwer Law International, The Hague.

[11] Caris, A., Macharis, C. and Janssen, G.K. (2008) Planning Problems in Intermodal Freight Transport: Accomplishments and Prospects. Transportation Planning and Technology, 31, 277-302.

[12] Panayides, P.M. (2002) Economic Organization of Intermodal Transport. Transport Reviews, 22, 401-414. http://dx.doi.org/10.1080/01441640210124523

[13] United Nations Convention on International Multimodal Transport of Goods. Geneva, 24 May 1980.

[14] NSW Government, Bureau of Transport Statistics (2011) Transport Customer Survey, Customer Satisfaction with Public Transport System. Sydney.

[15] Neely, A., Gregory, M. and Platts, K. (1995) Performance Measurement System Design: A Literature Review and Research Agenda. International Journal of Operations \& Production Management, 15, 80-116. http://dx.doi.org/10.1108/01443579510083622

[16] Bontekoning, Y. and Priemus, H. (2004) Breakthrough Innovations in Intermodal Freight Transport. Transportation Planning and Technology, 27, 335-345. http://dx.doi.org/10.1080/0308106042000273031

[17] Pizam, A. and Ellis, T. (1999) Customer Satisfaction and Its Measurement in Hospitality Enterprises. International Journal of Contemporary Hospitality Management, 11, 326-339. http://dx.doi.org/10.1108/09596119910293231

[18] Grigrousdis, E. and Siskos, Y. (2003) A Survey of Customer Satisfaction Barometers: Some Results from Transportation Communications Sector. European Journal of Operational Research, 152, 334-353.

[19] United Nations Economic Commission for Africa (2003) Issues on Multimodal Transport Development in Africa. Addis Ababa.

\section{Annex}

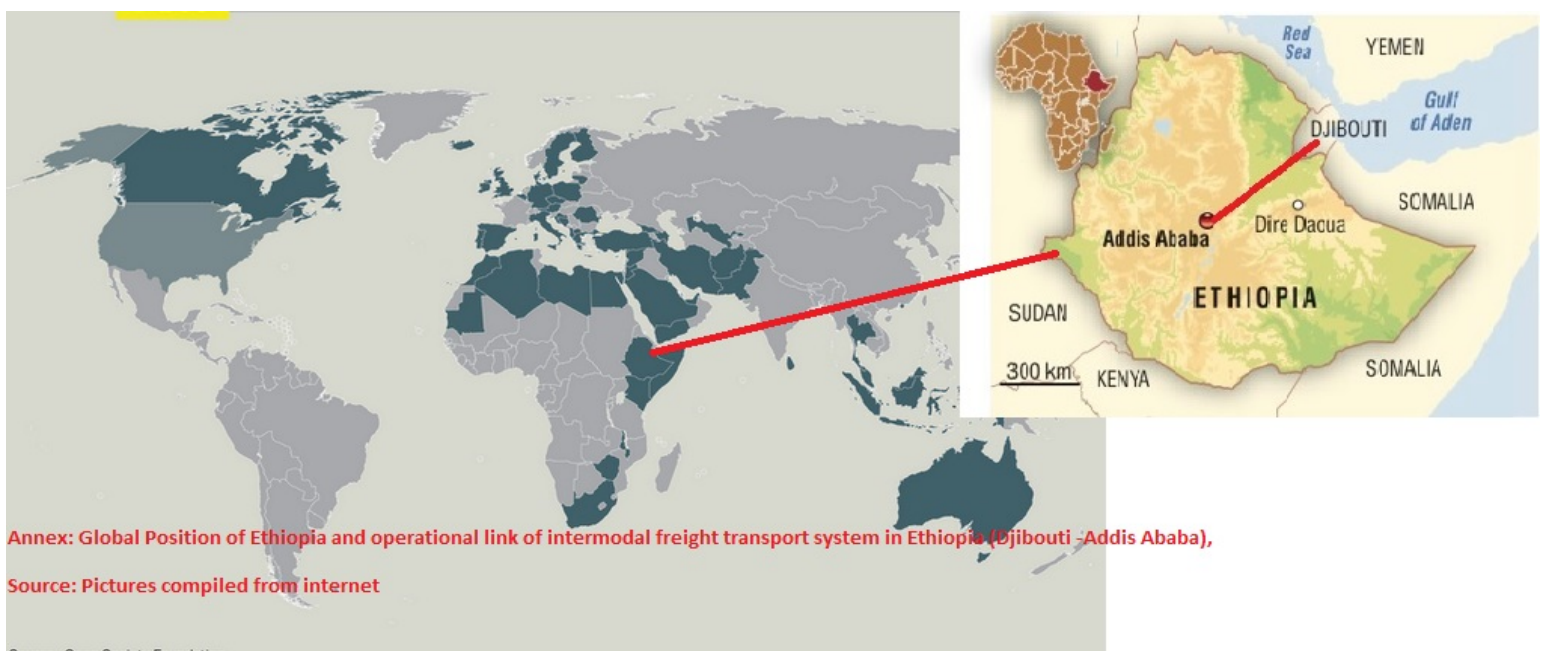


Scientific Research Publishing (SCIRP) is one of the largest Open Access journal publishers. It is currently publishing more than 200 open access, online, peer-reviewed journals covering a wide range of academic disciplines. SCIRP serves the worldwide academic communities and contributes to the progress and application of science with its publication.

Other selected journals from SCIRP are listed as below. Submit your manuscript to us via either submit@scirp.org or Online Submission Portal.
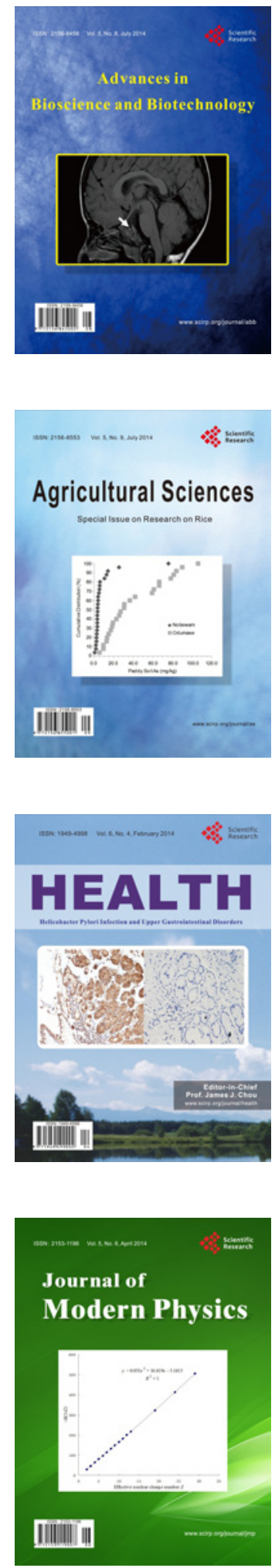
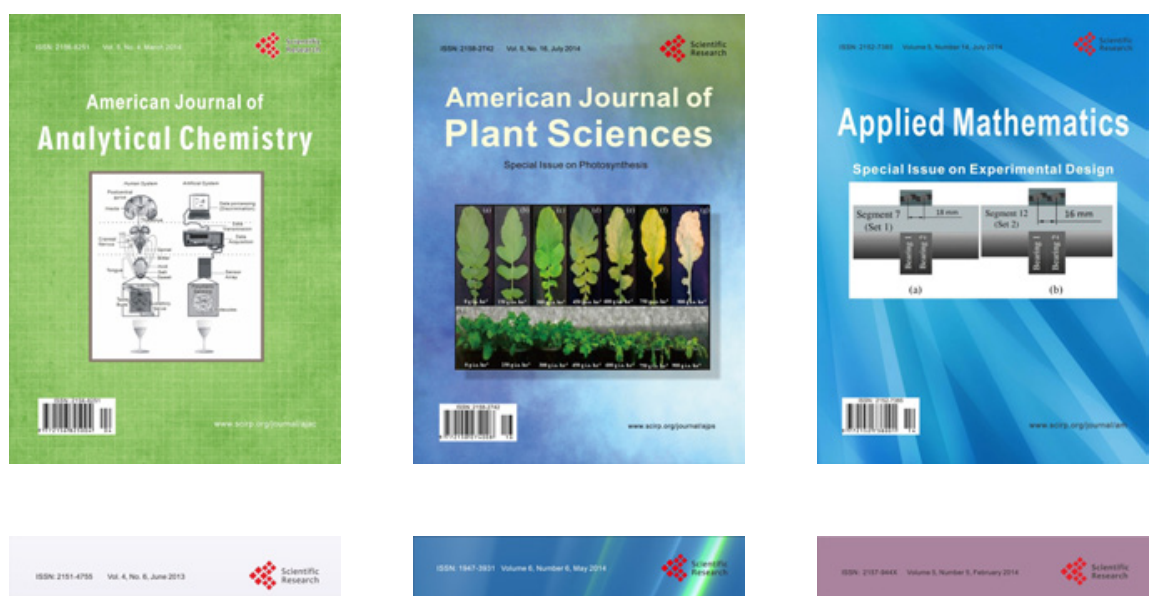

Creative Education
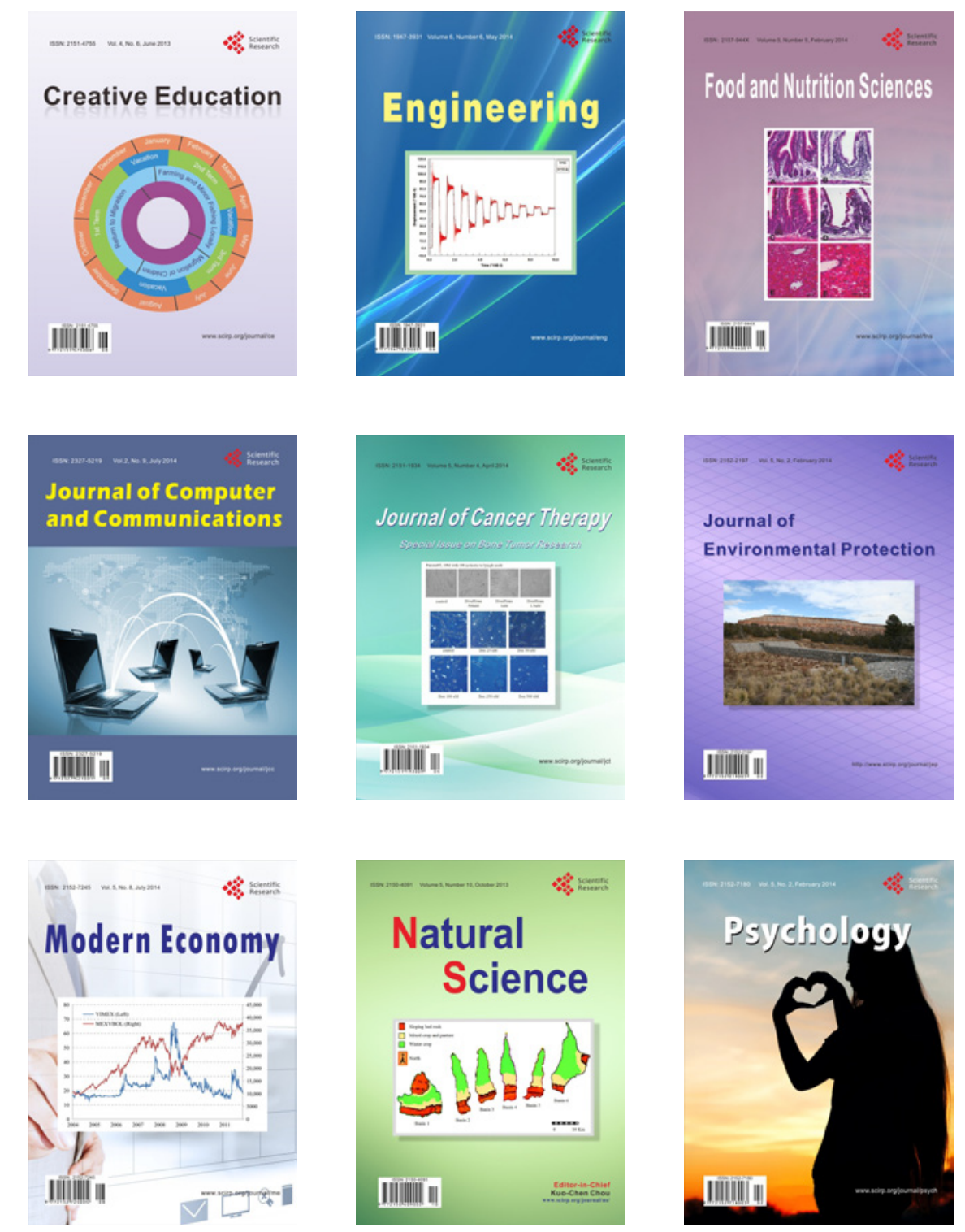